\title{
PENGGUNAAN PIR T-LOOP UNTUK PERBAIKAN INKLINASI (MESIAL TIPPING) GIGI MOLAR KEDUA PERMANEN RAHANG BAWAH
}

Shella Indri Novianty ${ }^{*}$

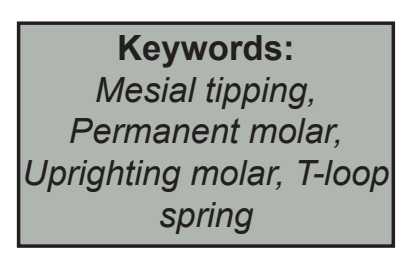

\section{ABSTRACT}

Background: Mesial tipping of permanent molar could be corrected by many ways. One of the simplest way was by using T-loop spring. Objective: To report the result of using straight wire appliance system Roth with $\neg$ T-loop spring in order correction of mesial tipping of second lower permanent molar on both side. Case Management: A 35 years old woman came with chief complain wanted to fix the lower left and right molar which was tilted and felt uncomfortable during mastication. OPG examination showed a mesial tipping of 37 and 47 tooth with 300 and 550 angulations. The measurement of angulations was using modification of the midline reference plane as used by Elsey and Rock. The straight wire appliance system Roth with .022" slot was used for the treatment. T-loop spring with .018x.022" rectangular stainless steel wire was used to upright of both second permanent molars. Observation of 4 months treatment using T-loop spring showed an improvement in angulations of both second molars; 550 on 37 and 630 on 47.

Conclusion: Mesial tipping correction of second permanent molar can be accomplished using T-loop spring with stainless steel rectangular .018x.022" wire and consistently yields satisfactory result.

\section{PENDAHULUAN}

Perubahan inklinasi gigi molar kedua permanen ke arah mesial atau yang kerap disebutdengan mesialtipping dapat disebabkan oleh hilangnya gigi molar pertama permanen (misalnya dikarenakan oleh ekstraksi) dalam jangka waktu yang cukup lama dan tidak digantikan oleh protesa. Perubahan posisi gigi ini dalam jangka panjang, tentu akan menyebabkan perubahan patologis salah satunya pada gingiva dan jaringan pendukung disekitar gigi tersebut ${ }^{1,2}$. Berbagai macam bentuk malposisi gigi, secara signifikan akan mempengaruhi perubahan pada jaringan periodontal seperti menyebabkan terjadinya gingivitis kronis, pembesaran gingiva, resesi gingiva, dan periodontitis kronis. Oleh karena itu, perawatan ortodontik penting dilakukan untuk mengkoreksi malposisi gigi individual agar tercapai peningkatan kesehatan gigi dan mulut $^{3}$.

Perbaikan mesial tipping gigi molar dapat dilakukan dengan 2 cara, yaitu 1) melalui pergerakan mahkota gigi ke arah distal (distal crown tipping) yang akan menghasilkan ruangan untuk protesa baik lepasan, cekat atau implan, 2) melalui pergerakan akar gigi ke arah mesial (mesial root tipping) yang akan menyebabkan pengurangan ruang sehingga mengurangi kemungkinan untuk penggunaan protesa. Pergerakan akar gigi ke arah mesial ini sedikit sulit untuk dicapai terutama ketika telah terjadi resorbsi tulang alveolar yang cukup banyak pada regio gigi yang hilang². Terdapat banyak cara yang dapat digunakan untuk memperbaiki mesial tipping gigi molar, seperti penggunaan kawat lentur dengan ukuran besar, berbagai macam spring atau pir seperti helical spring, box-loop spring, T-Loop

*Department Orthodonsia, Faculty of dentistry, Universitas Islam Sultan

Korespondensi: drg.shellaindri@gmail.com 
spring, dan lain-lain, penggunaan mini-implant (TAD), dan bahkan pada kasus mesial tipping dengan derajat sangat berat dapat dilakukan tindakan operasi $i^{4,5,6}$.

Pir T-loop dan beberapa pir lain seperti tear drop loop, key hole loop,dan omega loop biasanya digunakan untuk retraksi anterior dengan mekanisme frictionless1. Pir T-loop merupakan salah satu pir yang sangat mudah untuk dibuat dan memberikan hasil perawatan yang sangat memuaskan untuk koreksi mesial tipping gigi molar permanen.. Pir T-loop ini dibuat dengan menggunakan kawat stainless steel (SS) penampang rektangular ukuran $.017 x .025$ inchi.

Laporan kasus ini bertujuan untuk menampilkan bahwa penggunaan pir T-loop sangat efektif untuk memperbaiki inklinasi (mesial tipping) gigi molar kedua permanen rahang bawah dan pir ini sangat mudah dan cepat untuk dibuat dalam kegiatan praktek ortodontis sehari-hari6.

\section{LAPORAN KASUS}

Pasien wanita berumur 35 tahun, pada bulan Oktober 2016 datang dengan keluhan ingin memperbaiki posisi gigi geraham kiri dan kanan bawah yang miring dan dirasa sangat tidak nyaman ketika digunakan untuk mengunyah. Pasien datang dalam kondisi sedang dalam perawatan ortodontik menggunakan straight wire appliance sistem Roth dengan slot .022" oleh dokter gigi lain di luar kota dan menyatakan ingin pindah perawatan ortodontik. Berdasarkan hasil anamnesis diketahui bahwa pasien telah menggunakan alat ortodontik cekat tersebut selama kurang lebih 2 tahun dan telah lama mencabutkan gigi geraham pertama permanen rahang bawah baik pada sisi kiri maupun kanan
Berdasarkan pemeriksaan dari ronsen panoramik (OPG) terlihat bahwa pada rahang atas pasien tidak memiliki gigi kaninus permanen kiri dan kanan, Pada rahang bawah terlihat bahwa pasien tidak memilki gigi 38, 36, dan 46. Pada ronsen juga terlihat bahwa gigi 37 dan 47 mengalami mesial tipping dengan angulasi sebesar 300 untuk gigi 37 dan 550 untuk gigi 47 (Gambar 1).

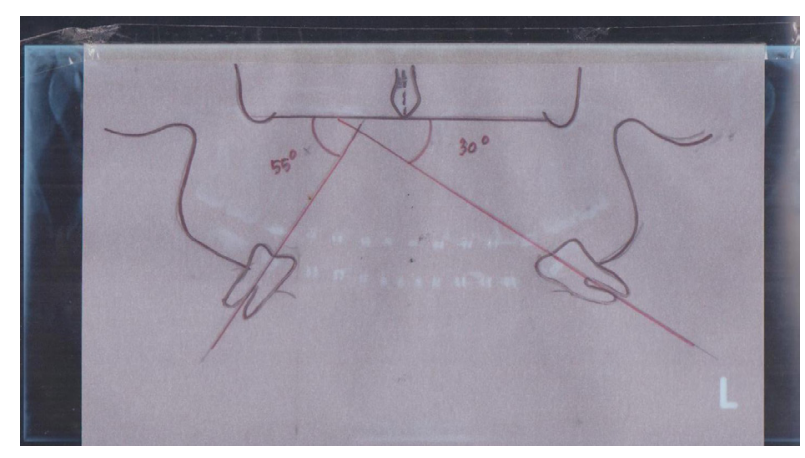

Gambar 1. Hasil OPG dan Angulasi gigi molar permanen kedua kanan dan kiri sebelum perawatan

Pengukuran angulasi gigi dilakukan berdasarkan metode modifikasi bidang referensi midline yang dipakai oleh Elsey dan Rock (Gambar 2) dengan cara sebagai berikut, dilakukan tracing untuk septum nasal dan ANS, kemudian ditarik garis yang membagi septum nasal menjadi dua. Setelah itu ditarik garis sepanjang bidang palatal yang tegak lurus terhadap garis bagi septum nasal. Bidang ini disebut dengan bidang referensi horizontal (HRP). Molar kedua permanen kiri dan kanan kemudian ditapak dan ditentukan aksisnya. Aksis masing-masing gigi digambar dari pertengahan mahkota gigi memanjang sampai bifurkasio gigi. Garis aksis ini kemudian diperpanjang sampai menyentuh HRP dan kemudian dilakukan pengukuran angulasi dari masing-masing gigi ${ }^{7}$ Metode pengukuran seperti terlihat pada gambar di bawah ini: 


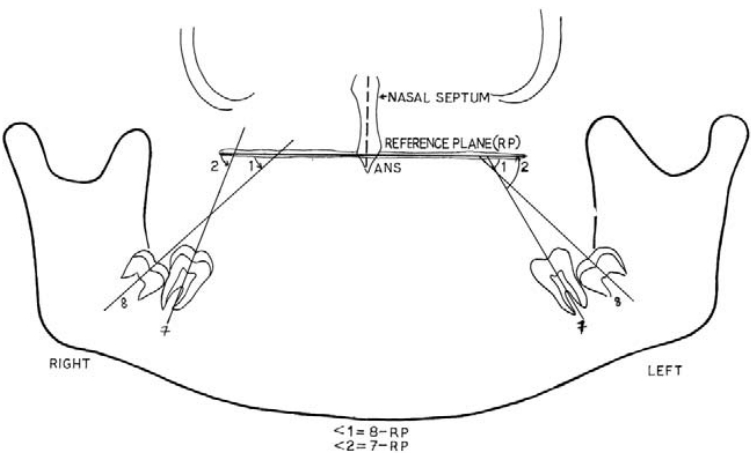

Gambar 2. Diagram pengukuran angulasi gigi Molar ${ }^{4}$

Perawatan ortodontik pada pasien ini tetap menggunakan straight wire appliance sistem Roth slot .022" dan menggunakan molar band pada kedua geraham untuk menggantikan bondable buccal tube yang dipakai sebelumnya. Tahap awal leveling dan unraveling dilakukan secara bertahap dimulai dengan menggunakan kawat $\mathrm{Ni}$-Ti diameter .014" sampai Ni-Ti rektangular ukuran .018x.022". Perbaikan mesial tipping gigi 37 dan 47 menggunakan kawat SS rektangular ukuran .018x.022" dengan pir T-loop di mesial masing-masing geraham dan di interdental gigi kaninus dan premolar pertama (P1) bawah kiri dan kanan. Ligasi dilakukan pada gigi kaninus sampai premolar kedua (P2) Pada saat insersi kawat, akhiran kawat ditarik lebih ke distal melewati buccal tube dan dilakukan chinced back agar terjadi pembukaan T-loop sebesar 1-2 $\mathrm{mm}$ dan ruang di mesial gigi 37 dan 47 dapat berkurang. Pada pasien ini belum digunakan kawat SS rektangular ukuran .017x.025" dikarenakan ketertidaksediaan bahan. Desain pir T-loop seperti pada gambar 3 di bawah ini:

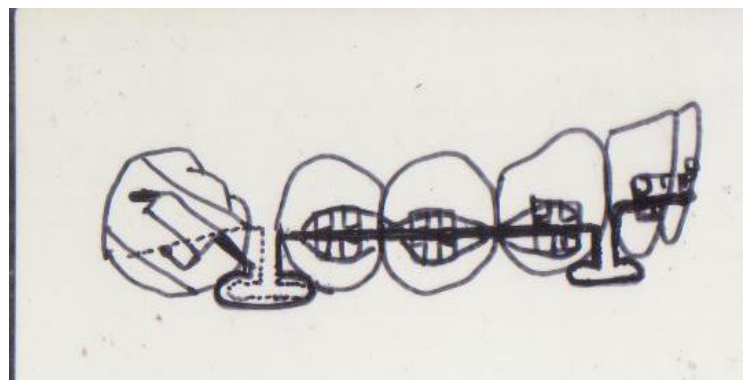

Gambar 3. Desain pir T-loop pada kasus

Empat bulan setelah pemakaian pir T-loop telah terlihat perubahan yang cukup signifikan pada angulasi kedua gigi M2 kiri dan kanan bawah, yaitu sebesar 630 untuk 47 dan 550 untuk gigi 37. Perubahan angulasi pada kedua gigi geraham bawah dapat terlihat seperti pada gambar 4 di bawah ini:

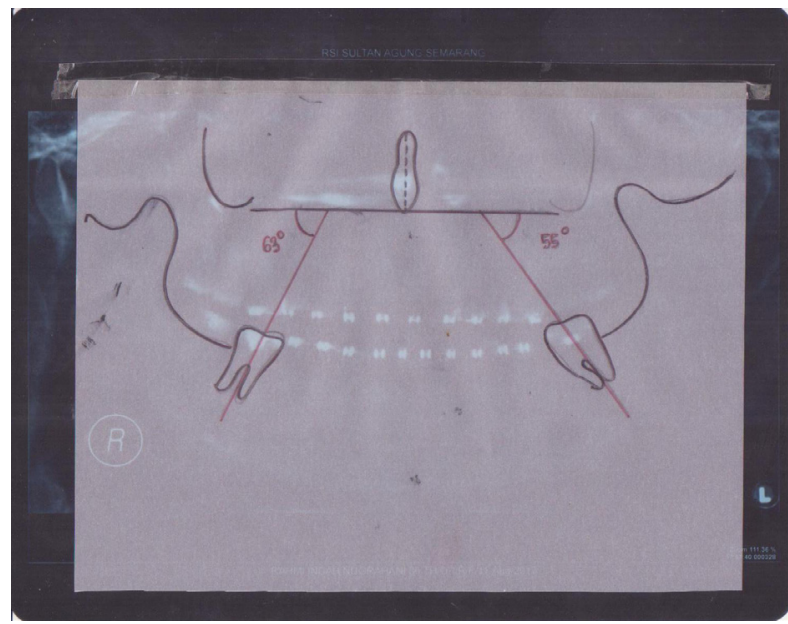

Gambar 4. Perubahan Angulasi pada kedua gigi molar.

Pada pemeriksaan model studi terlihat bahwa terdapat celah antara gigi P2-M2 kiri bawah sebesar $3 \mathrm{~mm}$ sedangkan sebelum perawatan terdapat celah pada regio tersebut sebesar $5 \mathrm{~mm}$. Pada regio kanan, sebelum perawatan, terdapat celah sebesar $2 \mathrm{~mm}$ diantara gigi P2-M2 kanan bawah, sedangkan setelah perawatan tidak terdapat celah pada regio tersebut. Pada model studi juga terlihat 

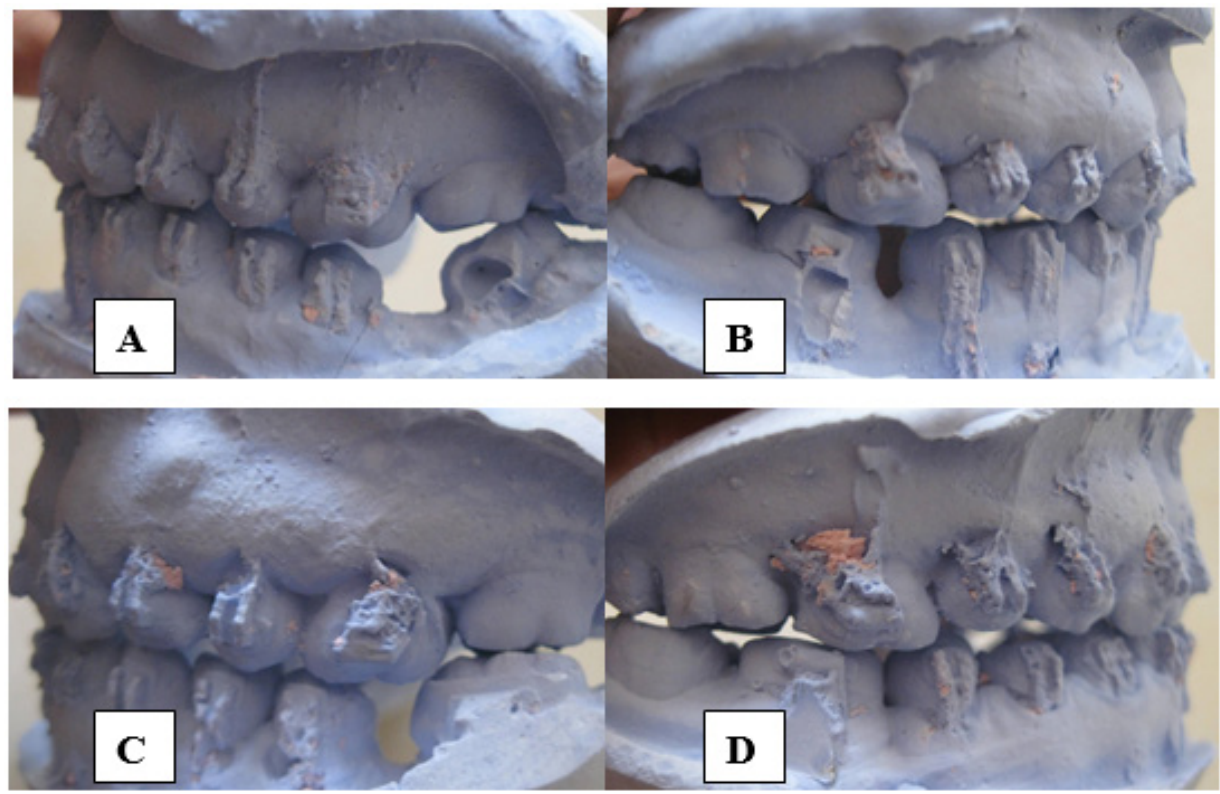

Gambar 5. A) Molar kedua permanen RB sisi kiri sebelum perawatan, B) Molar kedua permanen RB sisi kiri sebelum perawatan, C) Molar kedua permanen RB sebelah kiri setelah pemakaian pir T-loop, D) Molar kedua permanen RB sisi kanan setelah pemakaian pir T-loop

perbaikan oklusi pada regio gigi posterior kiri dan kanan, seperti yang telihat pada gambar 5 .

\section{DISKUSI}

Perbaikan inklinasi gigi molar pada dasarnya dapat dilakukan dengan 2 cara yaitu dengan melakukan distal crown tipiing dan mesial root tipping. Pada distal crown tipping, penggunaan kawat rektangular $\mathrm{Ni}-\mathrm{Ti}$ .017x.025" sudah cukup untuk menghasilkan gaya sebesar 100 gram dan mengkoreksi mesial tipping gigi molar dalam derajat ringan. Apabila molar tipping dalam derajat berat atau parah maka penggunakaan kawat secara penuh dari gigi molar ke molar akan menyebabkan gigi premolar kedua mengalami tipping ke arah distal, dan hal ini sangat tidak diinginkan. Oleh karena itu, penggunaan kawat SS .019x.025" secara sectional atau segmental pada gigi kaninus sampai premolar kedua dan penggunaan pir tambahan dari kawat berukuran .017x.025" beta-Ti tanpa helical loop atau kawat SS .017x.025" dengan loop untuk menambah kelentingan kawat, menjadi pilihan yang baik untuk koreksi mesial tipping gigi molar dengan melakukan distal crown tipping (Gambar 6). Perbaikan inkinasi gigi molar dengan distal crown tipping akan menyebabkan pelebaran celah di mesial gigi molar tersebut yang dapat digunakan untuk gigi tiruan (Gambar 7)2.

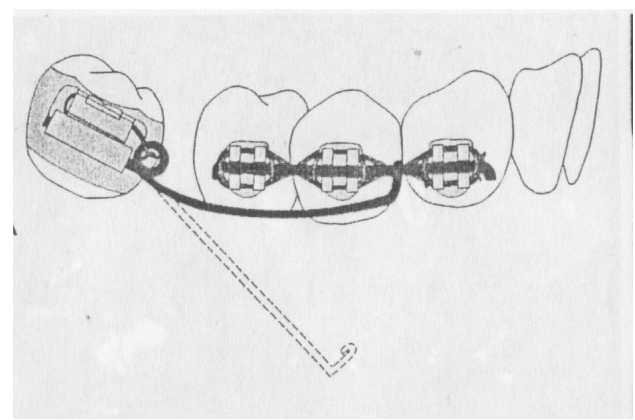

Gambar 6. Desain alat untuk koreksi mesial tipping dengan melakukan distal crown tipping2 
A

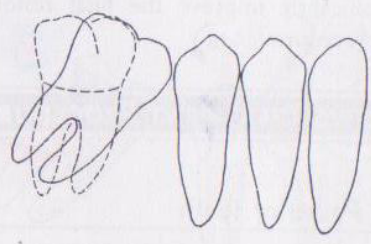

B

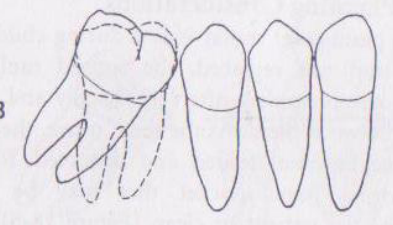

Gambar 7. A) Koreksi mesial tipping gigi molar dengan cara distal crown tipping, B) Koreksi mesial tipping dengan cara mesial root tipping ${ }^{2}$

Berkebalikan dari distal crown tipping, perbaikan inklinasi gigi molar dengan mesial root tipping dapat menyebabkan pengurangan celah di mesial gigi molar yang mengalami tipping, sehingga memperkecil kemungkinan untuk pemakaian gigi tiruan pada regio tersebut (gambar 7). Pada mesial root tipping untuk koreksi inklinasi gigi molar permanen, dapat digunakan pir T-Loop menggunakan kawat .017x.025" SS yang dipasang secara sectional dari gigi kaninus ke gigi molar. Apabila rencana perawatan bertujuan untuk menjaga atau mengurangi celah di mesial gigi molar, maka akhiran distal dari kawat dengan pir T-loop dapat ditarik lebih ke distal melalui buccal tube sehingga T-loop akan terbuka 1-2 $\mathrm{mm}$ dan akhiran kawat ditekuk ke arah gingival. Perlakuan ini akan menimbulkan gaya mesial pada gigi molar dan bekerja berlawanan arah dengan gaya tipping mahkota ke arah distal pada saat koreksi inklinasi gigi molar (uprighting). Apabila dalam rencana perawatan masih diinginkan ada celah di mesial gigi molar yang mengalami tipiing, maka pada akhiran distal kawat, tidak perlu ditekuk supaya gigi dapat bergeser ke distal (Gambar 8)².

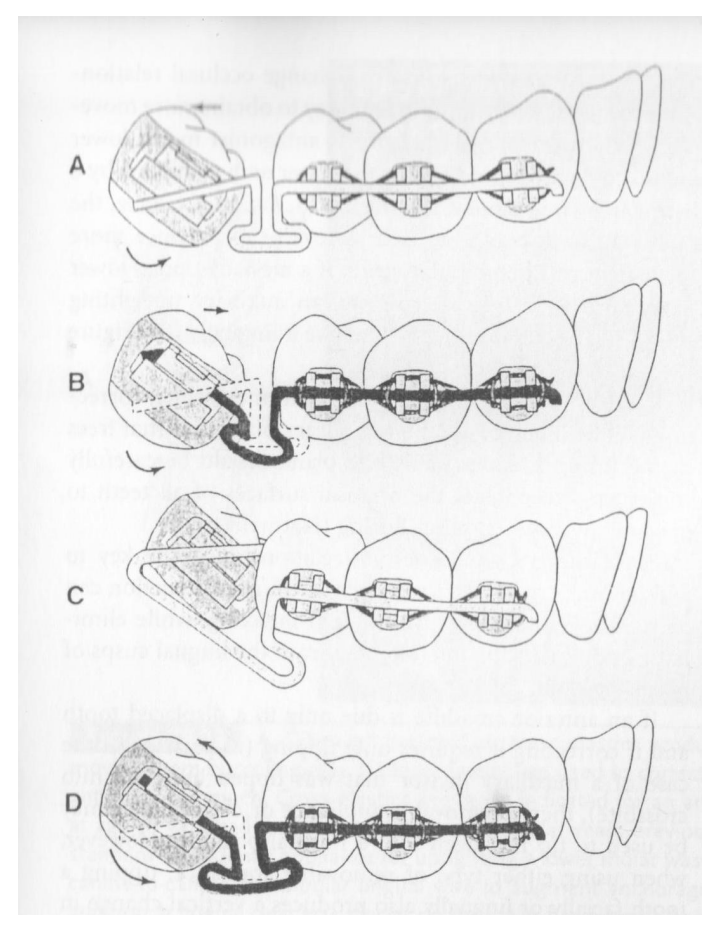

Gambar 8. Desain alat pir T-loop

Pada kasus ini operator memilih untuk melakukan mesial root tipping dengan menggunakan T-loop dan akhiran distal kawat yang ditekuk agar memperkecil celah di mesial gigi M2 kiri dan kanan, sehingga hasil perawatan menunjukkan pada sisi kanan celah di mesial gigi M2 sudah tidak ada dan pada sisi kiri berkurang menjadi $3 \mathrm{~mm}$. Kawat yang digunakan adalah kawat SS rektangular dengan ukuran .018x.022" dan tidak sectional atau segmental. Untuk mencegah terjadinya pergerakan ke distal dari gigi premolar kedua dan atau pergerakan gigi lain yang tidak diinginkan, maka pada distal gigi kaninus kiri dan kanan juga diberi T-loop, serta adanya ligasi pada gigi kaninus sampai P2 kiri dan kanan bawah. Pemakaian kawat .018x.022" digunakan untuk koreksi inklinasi gigi M2 kiri dan kanan bawah dikarenakan kawat .017x.025" tidak tersedia, walaupun demikian, hasil koreksi inklinasi gigi M2 kiri dan kanan masih cukup memuaskan. Hal ini terlihat dari 
adanya perubahan sudut angulasi gigi-gigi M2 tersebut. Pada gigi M2 kiri bawah terjadi peningkatan sudut sebesar 250 (sudut awal sebesar 300 dan akhir sebesar 550) dan pada M2 kanan bawah sebesar 80 (sudut awal sebesar 550 dan akhir sebesar 630).

Penggunaan pir T-loop memberikan keuntungan berupa pergerakan gigi yang terkontrol, dapat diterima oleh pasien, dan memberikan gaya ringan dan berkelanjutan untuk menghasilkan pergerakan gigi yang cepat, Kecepatan hasil perawatan untuk koreksi inklinasi gigi molar dengan pir T-loop salah satunya juga dipengaruhi oleh jumlah gigi yang membutuhkan perbaikan, akan tetapi rata-rata membutuhkan waktu perbaikan sekitar 8-16 minggu ${ }^{6}$.

\section{KESIMPULAN}

$\begin{array}{lrr}\text { Penggunaan Pir } & \text { T-Loop dengan } \\ \text { menggunakan kawat } & \text { stainless } & \text { steel } \\ \text { penampang rektangular } & \text { dengan } & \text { ukuran } \\ \text {.018x.022", untuk perbaikan inklinasi (mesial } & \text { tipping) gigi molar kedua permanen rahang } \\ \text { bawah, memberikan hasil yang memuaskan. }\end{array}$

\section{DAFTAR PUSTAKA}

1. Iyyer,B.S.,Orthodontics The Art and Science, Arya (Medi) Publishing House, New Delhi, 2004, p. 326-7

2. Proffit, W.R., Fields, H.W, and Sarver, D.M., Contemporary Orthodontics Fourth Edition, Mosby Elsevier, St.Louis, 2007, p.639-43

3. Gusmao, E.S., Coutinho de Querioz,R.D., Coelho, R.d.S., Cimoes,R., and Lima dos Santos,R., Association Between Malpositioned Teeth and Periodontal Disease, Dental Press J Orthod, 2011, July-Aug 16(4):87-94

4. Allagayer, S., Platcheck, D., Vargas,I.A., and Loro, R.C.D., Mini-Implants: Mechanical Resource for Molar Uprighting, Dental Press J Orthod, 2013, JanFeb 18(1):134-42
5. Shpack,N., Finkelstein,T., Lai,Y.H., Kuftinec,M.M., Vardimon,A., and Shapira,Y., Mandibular Permanent Second Molar Impaction Treatment Options and Outcome, Open Journal of Dentistry and Oral Medicine, 2013, 1(1):9-14

6. Tuncay,O.C., Biggerstaff,R.H., Cutcliffe,J.C., and Berkowits,J., Molar Uprighting with T-loop Spring, JADA, 1980, Vol.100:863-6

7. Jain,S., and Valiathan,A., Influence of First Premolar Extraction on Mandibular Third Molar Angulation, Angle Orthodontist, 2009, Vo.79 no.6 